\title{
Fun, influence and competence-a mixed methods study of prerequisites for high school students' participation in physical education
}

\author{
Eirik Abildsnes $^{1 *}$ (D) Gudrun Rohde ${ }^{2}$, Sveinung Berntsen ${ }^{3}$ and Tonje H. Stea ${ }^{3}$
}

\begin{abstract}
Background: Many adolescents do not reach the recommended levels of physical activity (PA), and students attending vocational studies are less committed to take part in physical education (PE) than other students. The purpose of the present study was twofold: 1) to examine differences in physical activity, diet, smoking habits, sleep and screen time among Norwegian vocational high school students who selected either a PE model focusing on PA skills, technique and improvement of physical performance ("Sports enjoyment") or more on health, play and having fun when participating in PE lessons ("Motion enjoyment"), and 2) to explore the students' experiences with PE programs.

Methods: In this mixed methods study 181 out of 220 invited students (82\%) comprising 141 (78\%) girls and 40 (22\%) boys attending vocational studies of Restaurant and Food Processing (24\%), Design, Arts and Crafts (27\%) or Healthcare, Childhood and Youth Development (49\%) were recruited for participation in the new PE program. PA level, sedentary time and sleep were objectively recorded using the SenseWear Armband Mini. A self-report questionnaire was used to assess dietary habits, smoking and snuffing habits, use of alcohol, screen use and active transportation. Four focus group interviews with 23 students ( 12 boys) were conducted to explore how the students experienced the new PE program.

Results: Students attending "Motion enjoyment" accrued less steps/day compared to the "Sports enjoyment" group $(6661(5514,7808)$ vs.9167 $(7945,10390)$ steps/day) and reported higher screen use (mean, 3.1; 95\% Cl, 2.8, 3.5) vs. 2.4 $(2.0,2.9)$ hours/day). Compared to those attending "Sports enjoyment", a higher number of students attending "Motion enjoyment" reported an irregular meal pattern (adjusted odds ratio, 5.40; 95\% confidence interval (CI), 2.28, 12.78), and being a current smoker $(12.22(1.62,107.95))$. The students participating in the focus group interviews emphasized the importance of having competent and engaging teachers, being able to influence the content of the PE program themselves, and that PE classes should include a variety of fun activities.

Conclusion: Students selecting "Motion enjoyment" accrued less steps/day and reported overall more unhealthy lifestyle habits, including higher screen time, a more irregular meal pattern and a higher number were current smokers, compared to those selecting "Sports enjoyment". Program evaluation revealed that both groups of students valued competent PE teachers and having influence on the content of the PE program.
\end{abstract}

Keywords: Adolescents, Healthy lifestyle, Focus groups, Physical activity, Health promotion

\footnotetext{
* Correspondence: eirik.abildsnes@kristiansand.kommune.no

'Department of Global Public Health and Primary Care, University of Bergen,

Bergen, Norway

Full list of author information is available at the end of the article
} 


\section{Background}

Globally, $80 \%$ of adolescents do not reach the recommended levels of physical activity (PA) [1]. In Norway $87 \%$ of girls and $96 \%$ of boys participate in moderate intensity PA for at least $60 \mathrm{~min}$ a day at the age of 6 years, but at the age of 15 years only $43 \%$ of girls and $58 \%$ of boys reach this recommended level of PA [2]. Regular PA has beneficial short-term effects on physical, mental and social aspects of health among adolescents, and may improve self-esteem [3] and reduce symptoms of anxiety and depression [4]. Participation in PA has also been positively associated with academic performance in children and adolescents [5, 6]. Results from tracking of PA level indicate that a physically active lifestyle develops in early childhood and that the stability of PA is moderate or high from youth to adulthood [7]. Furthermore, strong evidence show long-term effects of PA in adulthood on rates of major non-communicable diseases, life expectancy, and the cost of health care spending $[8,9]$.

Schools may serve as an important arena for achieving public health goals in conjunction with their educational commitments [10]. Physical education in schools is universally applicable, and a systematic review has concluded that school-based programs might increase the students' level of moderate-to-vigorous intensity physical activity (MVPA) [11]. Another systematic review of follow-up studies concluded that studies based on a theoretical framework and lasting longer than 1 year, were effective in producing sustained impact on PA habits and most likely on fundamental movement skills [12]. Results from another study have indicated a positive impact of early required physical education (PE) upon adult PA [13].

Self-determination Theory (SDT) identifies autonomy, perceived competence and relatedness as fundamental psychological needs [14]. Students enjoy participation in PE when they have a choice of activities, feel competent, in control and supported by their peers and teachers [15]. Determinants of PA level in a population includes individual factors such as age, sex, health status, self-efficacy, and previous PA as well as physical and environmental factors like economic conditions, societal norms, urbanisation and industrialisation [16]. Studies have suggested that the following important factors should be included as essential parts of PA and PE programs; involvement of competent PE teachers, support from family and community stakeholders, as well as considerations about how social, behavioural, demographical, biological, environmental, psychological and cognitive factors influence PA $[17,18]$. Furthermore, adolescents should be encouraged to take part in program development, selecting activities that generate fun, enjoyment and interest $[19,20]$. PE programs based on these principles may support intrinsic motivation and adherence to PA $[21,22]$. It is also suggested that knowledge about the target population's background and preferences should be included in intervention studies of PA among adolescents [23].

The intention of PE programs in Norwegian high schools is to inspire students to experience enjoyment and lifelong adherence to participation in PA, and develop a positive perception of body, self and identity [24]. To reach this goal, design of $\mathrm{PE}$ programs should intend to facilitate adherence to PA in general. A report from the World Health Organization (WHO) describes that adults with vocational education are less physically active than adults with college or university background in developed countries [25]. Thus, interventions intending to increase PA among adolescents should especially focus on students attending vocational studies. Even though attending PE is mandatory in Norwegian high schools, we in a previously published paper from the present study found that vocational students attend PE less frequently; have lower grades in PE and more frequently drop out of school than other high-school students [26, 27].

Few previously published studies have evaluated students' experiences of participation in PE programs and examined differences in objectively measured PA and between students choosing different PE models. In the present study, we compared students choosing a PE model based on personal preferences, focusing on PA skills, technique and improvement of physical performance ("Sports enjoyment") or more on health, play and having fun ("Motion enjoyment"), respectively. Specifically, we intended to 1) examine differences in MVPA, sedentary time, steps, sleep hours, screen time, diet, tobacco and alcohol use among students who selected the PE models "Sports enjoyment" and "Motion enjoyment", and 2) explore how the students experienced PA, PE and the new PE program.

\section{Methods}

In August 2013, two high schools in southern Norway introduced a new PE program to students attending their first year of vocational studies and invited the researchers to evaluate the new PE program. The students chose to participate in one out of two alternative PE models; 1) "Sports enjoyment" focusing on PA skills, in-depth knowledge of different sports, technique and improvement of physical performance, and 2) "Motion enjoyment" focusing less on technique and physical performance, but more on health benefits, achieving new experiences with PE, playing and having fun with sufficient intensity when participating in PE lessons. In the latter model, three groups of students attended PE class simultaneously, and the students could choose among three different activities. Three well-qualified PE teachers guided the activities. The students had to attend 
the chosen activity for the following 3 weeks, and then select another activity.

All students received the following information before choosing PE model: "If you choose "Motion enjoyment" PE class will contain activities that promote the joy of being physically active. If you choose "Sports enjoyment" PE class will contain more activities that develop your skills in different sports". The students attended PE class twice a week and had a total of $56 \mathrm{~h}$ of PE a year.

We used a mixed method study design. Data collection methods included both quantitative and qualitative measures to examine selected lifestyle habits of the participants and evaluate the PE program described above. A self-reported questionnaire was used to collect data and investigate differences in PA, dietary habits and tobacco use of the students selecting different PE models, and focus group interviews explored the students' adherence to PA and how they experienced the new PE program.

The mixed method analysis strategy represents a parallel mixed data analysis, with separate quantitative and qualitative strands implemented to answer related aspects of the research questions regarding the same phenomenon [28]. Inferences of each strand are integrated into metainferences at the end of the study, and presented in the discussion section.

The target group was students attending their first year of vocational studies at two high schools in the south of Norway, where PE teachers had experienced low student commitment in participating in PE [29]. During their first week at high school, the students received information about the PE program at meetings, via the intranet and by written information. After 6 weeks, the students were required to decide which PE model they wanted to join. During their first year in high school the students attending "Motion enjoyment" could choose between two or three different activities, lasting 3 weeks each. They were introduced to activities like climbing, swimming, yoga, orienteering and different ballgames. Some activities like dancing, outdoors and different net games were mandatory for both groups. The "Sports enjoyment" groups were introduced to different sports during the year, and focused on techniques and performance. Students who had an injury or other health complaints were taken care of by one of the teachers, finding some activity the student could manage. The students received evaluation with a 6-point grading scale with 6 as the best result. Evaluation was based on the students' efforts and achieved competence in the three main subject areas of the PE curriculum. These areas included exercise and lifestyle, outdoor life and sports activities.

In August 2013, 181 out of 220 invited students in 9 classes comprising 141 (78\%) girls and 40 (22\%) boys attending vocational studies of Restaurant and
Food Processing (24\%), Design, Arts and Crafts (27\%) or Healthcare, Childhood and Youth Development (49\%) were recruited for participation in the new PE program. In September 2013 all students were invited to fill in a questionnaire and no students were excluded. A total of 101 (24 boys) of the students (17 years old (SD 2.4)) agreed to wear a PA monitor (SenseWear $^{\mathrm{Tm}}$ Armband Mini, BodyMedia Inc., Pittsburgh, Pennsylvania, USA) for seven consecutive days in October 2013-January 2014. Furthermore, 23 of the students participating in the quantitative baseline study accepted to participate in a focus group study at the end of the intervention period in March-April 2014. Twelve of these students (6 boys) attended "Motion enjoyment" and 11 students (6 boys) attended "Sports enjoyment". The mean age of the students was 17 years (SD 2.6).

\section{Quantitative instruments \\ Physical activity}

The SenseWear Armband Mini (SWA) is a portable device that includes physiological parameters, including heat flux, skin temperature, galvanic skin response and movement (tri-axial accelerometer). SWA has been found valid for recordings of different aspects of physical activity as MVPA and sedentary time in a variety of populations including children and adolescents [30-33]. The participants were instructed to wear the SWA for seven consecutive days. They were instructed on how to wear the SWA and that it should be worn at all times except when taking a bath or shower. The SWA was worn on the left arm over the triceps branchii muscle at the midpoint between the acromion and olecranon processes. Data was downloaded and analysed with the manufacturer's software (SenseWear ${ }^{\text {rix }}$ Professional Research Software Version 8.1, BodyMedia Inc.). The summed value of 1-min epochs was used to estimate metabolic equivalents (METs) $\left(1 \mathrm{MET}=3.5 \mathrm{ml} \mathrm{O} \mathrm{O}_{2} \cdot \mathrm{kg}^{-1} \cdot \mathrm{min}^{-1}\right)$. Cut points defining MVPA were $\geq 3$ METs, cut points defining light PA were 1.6-2.9 METs and accumulated minutes were included. Sedentary time was defined as METs $\leq 1.5$. A day of recording was valid if the participant wore the SWA for at least 19.2 h, i.e. $80 \%$ of a $24-\mathrm{h}$ sampling period [34]. In the analysis we included only recorded data from adolescents with $\geq 1$ valid day of SWA wear time.

\section{The questionnaire}

The questionnaire was designed in the web-based online platform SurveyXact ${ }^{\mathrm{TM}}$ (Rambøll, Management Consulting, Oslo, Norway). The students used approximately 20-30 min to complete the questionnaire, with at least one member of the project group present to answer 
upcoming questions. To access the questionnaire, the participants had to open a webpage and enter the provided identification key.

The questions used in the present study has, in a previously published method study among 143 adolescents, aged 15-17 years, demonstrated test-retest reliability with an intraclass correlation coefficient (ICC) ranging from 0.68 to 0.99 [6].

The parental educational level was assessed with the question: "What level of education do your parents have?" The question had four response alternatives: (i) elementary school, (ii) high school, (iii) college or university ( $\leq 3$ years) and (iv) college or university ( $>3$ years). These response alternatives were then dichotomized into lower and higher education levels (lower $=$ no college or university education; higher = having attended college or university).

Meal frequency was assessed by the questions such as: "How often do you have breakfast each week?" The same was asked for lunch, dinner and evening meals. The items had five different response alternatives ranging from never to daily, which were dichotomized into having meals fewer than seven times a week (an irregular meal pattern) and having meals every day (a regular meal pattern). These dichotomous variables were then combined to create a summary variable referred to as "irregular all four meals", i.e. those skipping one of the main meals at least once a week versus those eating all meals every day.

Diet and beverage intake was assessed by asking: "How often do you eat/drink...?" All items had eight different response alternatives, ranging from never to more than once a day, and the response alternatives were further dichotomized into having high or low intake of the selected food items and drinks. Having soft drinks, sweets and candy and a salty snack $\geq 4$ times a week, respectively, was categorized as high intake. Having fruits, berries and vegetables less than once a day, was categorized as low intake.

Alcohol use was assessed by asking: "Have you ever consumed beer, wine or spirits?"

Smoking and snuffing habits were assessed by the question: "Do you smoke/use snuff?" The response alternatives were: "Have never smoked/snuffed; have tried smoke/snuff, but not anymore, have smoked/ snuffed regularly, but not anymore; smoking/snuffing, but not regularly and smoking/snuffing regularly and about_cigarettes/day." For the statistical analysis, those who reported smoking or snuffing occasionally or daily were classified as being a smoker/snuffer.

Television viewing and computer use was assessed as follows: "Excluding school hours on a regular weekday, how many hours do you watch TV or use PC/games?". Response alternatives were: "I don't watch TV or do gaming activity on a regular weekday, less than an hour a day, $1 \mathrm{~h}$ a day, $2 \mathrm{~h}$ a day, $3 \mathrm{~h}$ a day or $5 \mathrm{~h}$ or more a day" and presented as a continuous variable.

Information about active commuting was enquired about as follows: "How do you usually commute to/from school?" The response alternatives were: "Walking, cycling, bus, car, MC/scooter, other alternatives (open alternatives)." This variable was dichotomized into active commuting, which represented walking or cycling and non-active commuting.

\section{Statistical Analysis}

All statistical analyses were performed using SPSS version 22.0 (SPSS Inc., Chicago, IL). Statistical significance level was set to $5 \%$. Differences in continuous outcome variables (Table 1) between the two groups were assessed by analysis of covariance adjusting for age, parental education and mean valid days with recordings the SWA was worn (for the variables MVPA, steps, sedentary time and sleep hours). Adjusted means with 95\% CI are presented. The underlying assumptions of the analysis of covariance were assessed using Jackknife Residuals and Cook's d. The results are stratified on choice of PE model, presented as a percentage of participants reporting an irregular meal pattern, low intake of healthy food items and high intake of unhealthy food items and beverages in addition to being a current smoker or snuffer. Multiple logistic regressions were used to explore whether attending the PE model, "Motion enjoyment" was significantly associated with the health risk behaviors mentioned above, compared to attending "Sports enjoyment".

\section{Qualitative data}

We arranged 4 focus groups with 23 students (12 boys) attending "Sports enjoyment" and "Motion enjoyment", respectively in March and April 2014, when the students had participated in the new PE program for approximately 6 months. We audiotaped and transcribed the audiotapes verbatim. In analyses we used Systematic Text Condensation and an editing analysis style [35, 36]. Bracketing preconceptions, two researchers independently read the material searching for an overall impression and established preliminary subthemes. We then examined the text for units of meaning representing information about students' experiences with PA and PE and the new PE program. In an iterative process we coded and grouped these units, contrasted and abstracted the content in each group, and finally discussed and summarized the content of each group into generalized descriptions. To support analysis we used field notes and created mind maps, and discussed the analysis at each step to reach agreement. Quotations 
Table 1 Adjusted ${ }^{a}$ hours in daily moderate to vigorous intensity physical activity, steps, sleep and screen hours (TV/PC) presented by motion enjoyment and sport enjoyment. Data are given as adjusted means with 95\% confidence intervals (95\% Cl) in parentheses

\begin{tabular}{|c|c|c|c|}
\hline & $\begin{array}{l}\text { Motion enjoyment } \\
\text { Mean }(95 \% \mathrm{Cl})\end{array}$ & $\begin{array}{l}\text { Sport enjoyment } \\
\text { Mean }(95 \% \mathrm{Cl})\end{array}$ & $P$-value* \\
\hline Moderate-to-vigorous intensity PA (hours $\cdot$ day $^{-1}$ ) & $1.84(1.42,2.27)$ & $2.21(1.76,2.67)$ & 0.138 \\
\hline Steps per day & $6661(5514,7808)$ & $9167(7945,10390)$ & $<0.001$ \\
\hline Light PA (hours $\cdot$ day $^{-1}$ ) & $4.7(3.6,5.9)$ & $4.6(3.4,5.9)$ & 0.893 \\
\hline Sedentary time (hours $\cdot$ day $\left.^{-1}\right)^{b}$ & $11.1(9.8,12.4)$ & $10.7(9.3,12.1)$ & 0.572 \\
\hline Sleep (hours $\cdot$ day $^{-1}$ ) & $7.1(6.7,7.5)$ & $6.8(6.4,7.2)$ & 0.228 \\
\hline TV/PC (hours/day) ${ }^{c}$ & $3.1(2.8,3.5)$ & $2.4(2.0,2.9)$ & 0.006 \\
\hline
\end{tabular}

Abbreviations: PA Physical Activity

${ }^{*} P$-values for differences between groups, significant $p$-values given in bold

a Adjusted for age, sex and parental education and days with recordings

b Sedentary time, 06:00-23:59

c Data from questionnaire

were used to illustrate and support findings. More information about the qualitative methods used is available from the interview guide and a COREQ checklist [37] (Appendices 1 and 2).

\section{Results}

\section{Quantitative data}

Students who chose to enroll in "Sports enjoyment" accrued more steps/day compared to the "Motion enjoyment" group (9167 $(7945,10390)$ vs. $6661(5514,7808)$ steps/day) (Table 1). Neither MVPA, light PA, sedentary time, nor sleep hours were significantly different between the two groups of students (Table 1). The mean grades were 3.6 (3.1-4.2) and 2.8 (2.5-3.1) for students selecting "Sports enjoyment" and "Motion enjoyment", respectively.

All results from the questionnaire were adjusted for age, gender and parental education. Students attending "Motion enjoyment" reported higher TV/PC use compared to "Sports enjoyment" (mean $\pm 95 \%$ CI; 3.1 (2.8, $3.5)$ vs. 2.4 (2.0, 2.9) hours/day) (Table 1). 82.6\% (95\%CI; $75.8,89.5)$ attending "Motion enjoyment" and $77.1 \%$ $(64.8,89.4)$ attending "Sports enjoyment" reported no active commuting to school (Table 2).

Although the results showed no difference in consumption of single meals, attending "Motion enjoyment" was associated with irregular meal pattern (skip one or more of the main four meals during a day) (adjusted OR 5.40; 95\% CI, 2.28, 12.78) (Table 2). There were no differences in intake of fruit and berries, vegetables, soft drink, candy and salty snack, nor alcohol consumption debut between participation in the different PE models (Table 2). On the other hand, attending "Motion enjoyment" was associated with being a current smoker (13.22; 1.62, 107.95), but not snuffer (Table 2).

\section{Qualitative data}

All students described their previous and current experiences with PA and PE, and how they perceived their peers' attitudes towards taking part in PE class. They also expressed their preferences for PE. The qualitative results represent opinions of the students who participated in the focus groups.

\section{Previous PA and PE experiences}

The students attending both PE models reported diverging previous experiences with leisure-time PA and PE in junior high school, but the students attending "Sports enjoyment" more often reported positive engagement in leisure time PA. These previous experiences with $\mathrm{PE}$ and PA seemed to influence the students' attitudes towards PE. Some students attending both models reported low attendance to $\mathrm{PE}$ in their junior high school class, and that it had been easy to shirk PE class by faking injuries or sickness, or by deliberately forgetting fitness gear. Others reported high level of attendance and positive experiences of participating in PE. These students, attending both PE models, also had experienced devoted and inspiring PE teachers, and a variety of activities in PE class.

The students in my class [in junior high school] were eager to exercise, so everyone participated. It was fun. Some students participated less than others, but the PE teacher was aiming to get all students to be physically active (boy, "Motion enjoyment")

Other students described their PE teachers in junior high school as being lazy and not organizing stimulating PE activities. All students, however, reported limited expectations and experiences of learning outcome from PE in junior high school, and did not consider $\mathrm{PE}$ as a subject intending to increase competence of health and physical literacy. 
Table 2 Prevalence and adjusted odds ratio (AOR) of selected health-risk behaviors by participation in different models of physical education. Significant differences between groups is given in bold

\begin{tabular}{|c|c|c|c|c|c|c|}
\hline & \multicolumn{2}{|c|}{ "Motion enjoyment" } & \multicolumn{2}{|c|}{ "Sport enjoyment" } & \multirow[t]{2}{*}{$A O R^{a}$} & \multirow[t]{2}{*}{$95 \% \mathrm{Cl}$} \\
\hline & $\%$ & $95 \% \mathrm{Cl}$ & $\%$ & $95 \% \mathrm{Cl}$ & & \\
\hline Irregular breakfast & 70.3 & $62.0-78.5$ & 55.3 & $40.6-70.1$ & 1.73 & $0.82-3.63$ \\
\hline Irregular lunch & 68.6 & $60.2-77.0$ & 59.6 & $45.0-74.1$ & 1.51 & $0.72-3.17$ \\
\hline Irregular dinner & 40.5 & $31.6-49.4$ & 29.8 & $16.2-43.4$ & 1.87 & $0.86-4.09$ \\
\hline Irregular evening meal & 75.2 & $67.4-83.0$ & 63.8 & $49.6-78.1$ & 1.97 & $0.91-4.28$ \\
\hline $\begin{array}{l}\text { Irregular meal pattern } \\
(<4 \text { meals per day })\end{array}$ & 90.9 & $85.7-96.1$ & 80.9 & $69.2-92.5$ & 5.40 & $2.28-12.78$ \\
\hline $\begin{array}{l}\text { Low fruits and berries } \\
(<7 \text { times a week })\end{array}$ & 75.2 & $67.4-83.0$ & 66.7 & $52.8-80.5$ & 1.65 & $0.75-3.64$ \\
\hline $\begin{array}{l}\text { Low vegetables } \\
\text { ( }<7 \text { times a week) }\end{array}$ & 76.9 & $69.2-84.5$ & 64.6 & $50.6-78.6$ & 2.15 & $0.98-4.70$ \\
\hline $\begin{array}{l}\text { High regular soft drinks } \\
\text { ( } \geq 4 \text { times a week) }\end{array}$ & 32.2 & $23.8-40.7$ & 27.1 & $14.0-40.1$ & 1.42 & $0.63-3.20$ \\
\hline $\begin{array}{l}\text { High sweet and candy } \\
\text { ( } \geq 4 \text { times a week) }\end{array}$ & 26.5 & $18.5-34.4$ & 18.8 & $7.3-30.2$ & 1.16 & $0.48-2.81$ \\
\hline $\begin{array}{l}\text { High salty snack } \\
\text { ( } \geq 4 \text { times a week) }\end{array}$ & 14.9 & $8.4-21.3$ & 25.0 & $12.3-37.7$ & 0.47 & $0.19-1.14$ \\
\hline Have been drinking alcohol & 64.5 & $55.8-73.1$ & 63.8 & $49.6-78.1$ & 1.30 & $0.60-2.80$ \\
\hline Current smoker ${ }^{\mathrm{b}}$ & 19.0 & $11.9-26.1$ & 2.1 & $0.0-6.4$ & 13.22 & $1.62-107.95$ \\
\hline Current snuffer $^{\mathrm{b}}$ & 22.3 & $14.8-29.8$ & 14.9 & $4.3-25.5$ & 1.25 & $0.48-3.28$ \\
\hline No active commuting to school & 82.6 & $75.8-89.5$ & 77.1 & $64.8-89.4$ & 1.68 & $0.67-4.21$ \\
\hline
\end{tabular}

${ }^{a}$ Adjusted for age, sex and parental education

${ }^{\mathrm{b}}$ Self-reported smoking/snuffing sometimes or daily

The girls attending "Sports enjoyment" told about groups of other girls who skipped PE class because they did not want to expose an obese body, mess up their make-up or have to shower after class. The boys attending both PE models explained their own non-attendance in high school by injuries. The boys attending "Motion enjoyment" also reported missing the school bus, having back pain or having overslept when explaining nonattendance.

The students also told about their previous and present leisure time PA engagement. Some of the girls attending "motion enjoyment" described that they preferred to exercise at home or alone, doing yoga or running on a treadmill, and avoided visiting gyms or to participate in organized sports. These students often reported to take part in PA and PE to stay healthy. The boys attending this PE model most of all expected fun and enjoyment in PE class, but some of them wished to increase strength. Girls and boys attending "Sports enjoyment" more regularly participated in organized sports activities, and expressed ambitions of increasing physical fitness and strength. These students more often enjoyed visiting a gym,. Due to time constraints and part-time jobs, sports injuries or other health complaints, students attending both PE models had stopped attending organized sport activities when starting high school. Others had dropped out because they experienced too high ambitions in organized sport, even if they enjoyed being physically active and attending PE classes.

\section{I actually do nothing. I have tried many different activities, but never committed to a single sport activity or a gym (girl, "Sports enjoyment")}

\section{New PE experiences}

Overall, the students attending both PE models reported positive experiences with the new $\mathrm{PE}$ program. They appreciated being able to choose "Motion enjoyment" or "Sports enjoyment", being offered a variety of PE activities, and that PE teachers took into account that some students did not fancy traditional PE. All focus group participants reported a higher intensity in PE classes than they were used to in junior high school, and that most of their peers participated in PE classes. Students representing both PE programs appreciated that grading was mainly based on efforts rather than physical achievements, but some of them asked for tests to monitor improvement in physical fitness. 
If I just try to do my best now, I get better grades than I did in junior high school. Then I try even more. It is more fun to do my very best now (boy, "Motion enjoyment")

The girls attending "Motion enjoyment" appreciated being introduced to yoga. They described that yoga made them use several groups of muscles, and made it easier to relax and to cope with stress.

\section{If you have had a bad day or had a lot of stress, it [yoga] can be delicious (girl, "Motion enjoyment")}

Boys attending "Motion enjoyment" preferred other activities than yoga, but described that they experienced increased self-efficacy and enjoyment, and appreciated the variety of activities in PE class. The boys attending "Sports enjoyment" reported high intensity and engagement, a focus on improving techniques and succeeding to play as a team. All focus group participants reported that theoretical aspects of physical function and health was addressed in other study subjects, but reported some focus on diet and physical activity in PE class. A few of the students reported increased leisure time PA and physical fitness due to individual advice from their PE teacher. The girls attending "Sports enjoyment" enjoyed taking part in PE class, and appreciated a variety of activities.

More people take part in PE class. It is positive that more girls participate [in PE class]. It used to be opposite. Earlier, more boys attended. Now, it is more girls (girl, "Sports enjoyment")

The students also reported some negative experiences related to the new PE program. In the first period after implementation of the new PE models, the organization of PE classes was somewhat chaotic; the students experienced random decisions of individual grading and registration of attendance. Later on, the students reported that the organization of PE classes improved. More girls than boys attended to "Motion enjoyment". The boys attending this model missed activities intending to increase muscle strength, and in their opinion, this PE model was more tailored to girls' interests than boys'.

\section{To be honest, I miss an option of doing some real} exercise. Even if it is "Motion enjoyment" (boy, "Motion enjoyment")

Even if the PE program intended to tailor activities to fit the students' needs and interests, the students reported that they did not perceive that the program fully elicited the potential of each individual.

\section{Wishes for PE teaching}

All students recognized the PE teacher's role to be of crucial importance. They characterized the teacher as an important role model, and the teacher being in a power position in the student-teacher relationship. Teachers with professional skills and commitment, who recognized and followed up students individually and offered a variety of activities in PE class, were highly appreciated. The students also stated that they had a responsibility to engage themselves, to experience fun and enjoyment in PE class.

The teachers are clever and know what they are doing. If I needed help, then they help me. We have fun activities that I like, like climbing and swimming. So it is very nice (boy, "Motion enjoyment")

Students participating in both PE models appreciated the variation of $\mathrm{PE}$ activities included in $\mathrm{PE}$ classes, and also the opportunity to choose between the two models of PE. Although the students had different preferences with respect to what kind of activities they liked, they underscored a wish to participate in developing the program content. All focus group participants suggested that the PE classes should provide theory as well as practical information about diet and PA, and also a focus on injury prevention. They appreciated that students with injuries or other health complaints were offered individually tailored activities when they were unable to participate in regular PE classes.

Maybe the students could give some input to what we shall do in PE class. Of course the teacher shall decide, but it would be nice if the students had some influence. In the end, they are the ones who shall take part in PE class (girl, "Motion enjoyment")

\section{Discussion}

In the present study, we compared students choosing a PE model based on personal preferences, focusing on PA skills, technique and improvement of physical performance ("Sports enjoyment") or more on health, play and having fun ("Motion enjoyment"), respectively. Specifically, we intended to 1) examine differences in MVPA, sedentary time, steps, sleep hours, screen time, diet, tobacco and alcohol use among students who selected the PE models "Sports enjoyment" and "Motion enjoyment", and 2) explore how the students experienced PA, PE and the new PE program.

A majority of students in both groups met the recommendations of MVPA. However, students attending "Sports enjoyment" accrued more steps/day 
than those attending "Motion enjoyment". These results were supplemented by findings from the focus group interviews, which showed that students attending "Sports enjoyment" were more often engaged in sport clubs and competitions, whereas those attending "Motion enjoyment" preferred to exercise at home or alone and did not visit gyms or participate in organized sport. All students did not meet the recommended level of PA, and results from the focus groups also revealed decreased participation in PA with age among all students. These findings are in line with the results from a cohort study, which showed a decreased level of MVPA between 5 and 19 years of age [38]. In addition, the latter mentioned study identified four different MVPA patterns: 1) consistently inactive $(14.9 \%), 2)$ consistently active (18.1\%), 3) decreasing moderate intensity PA (52.9\%), and 4) substantially decreasing vigorous intensity PA (14.1\%). In the present study the students who participated in the focus groups described various reasons for stopping exercising with age, including time constraints as well as injuries and experiencing too high ambitions in organized sports.

Selecting "Motion enjoyment" was associated with a number of unhealthy lifestyle habits, including irregular consumption of main meals, smoking cigarettes and an increased number of cigarettes per day and an increased screen time. In line with the results from the present from the present study, a comprehensive review has confirmed that diet, PA and sedentary behaviours tend to cluster in both healthy and unhealthy behaviours, and that cluster patterns varied according to age, gender and socio-economic status [39]. Lifestyle habits adopted in childhood and adolescence may have impact on health in adulthood [7]. Thus the findings in the present study may perhaps reflect individual preferences, previous experiences with PA and social learning.

Previously published results based on findings reported by the same target group have shown a regular meal pattern, a high intake of healthy food items and being physically active were associated with increased odds of high academic achievement [6]. Having an irregular meal pattern is common among high school students, especially among vocational students [40]. Analyses based on both questionnaire data and interview data in the present study also indicated that the students choosing "Motion enjoyment" could benefit from an increased focus on different health behaviors, and despite low expectations of increased knowledge about healthy lifestyle habits, students participating in focus group interviews expressed a positive attitude toward learning more about healthy dietary habits, in addition to injury prevention and how to increase muscle strength in PE classes. Thus a potential exists for including an increased focus on theory and practical knowledge to increase physical literacy and health literacy in PE that may have an impact on future health risks [10].

In order to motivate participation in PE class, students participating in both PE models emphasized the importance of having a competent and engaging teacher, and including a varied selection of fun activities in PE class. A recently published systematic review confirmed that the content and design of $\mathrm{PE}$ programs may influence adherence to PE class and learning outcomes [18]. Furthermore, students who participated in focus group interviews expressed various experiences with leisure time $\mathrm{PA}$ and $\mathrm{PE}$ programs in junior high school. These experiences may also have influenced their choice of PE model in high school, and possibly their commitment to PA in general. A review study by Lai et al indicate that PE programs in schools have a potential to improve movement skills, generate fun, positive experiences and commitment to PA [12].

In the present study, mean MVPA was $1.8 \mathrm{~h}$ a day in the "Motion enjoyment" group vs. $2.2 \mathrm{~h}$ a day in the "Sports enjoyment" group. Thus many students in both groups met the recommendations of PA [2]. In a longitudinal study of PA habits among Norwegian adolescents, $85 \%$ of boys reported being physically active at least two-three times per week at age 16 and $52 \%$ at age 19 . Corresponding proportions for girls were 56 and $46 \%$, respectively [41]. The students who attended the focus groups explained that they spent less leisure time on PA due to time constraints and part-time jobs when starting high school. Others experienced organized sport as being too ambitious, even if they enjoyed being physically active and attending PE classes. Healthy lifestyle habits and PA levels are associated with academic achievements among adolescents [6], and lifestyle habits adopted in childhood and adolescence have impact on health in adulthood [7]. Thus positive experience of $\mathrm{PE}$ in high school is valuable with respect to health as well as academic results.

The students who participated in the focus groups underscored the importance of a competent and supporting PE teacher, who was willing to let the students influence the development of the PE program. This is in line with the basic psychological needs described in SDT, and supports the findings from a study of Bagøien et al [42]. In their study of Norwegian high school students' perceptions of PE, the importance of autonomy-supportive teachers in $\mathrm{PE}$ was positively associated with students' 
psychological needs satisfaction in PE and positively related to autonomous motivation for PE participation. In a previous published paper from the present study, PE teachers stated that they wanted to give their students an influence on the content of the PE program and facilitate fun and engagement without compromising with the framework of the education program and curriculum [27].

Strengths of the present study included the use of objectively measured PA, the high response rate, and the mixed method approach, which provided rich data on lifestyle-related topics and commitment to PA and PE. In addition, a multidisciplinary team of researchers conducted the study in close cooperation with PE teachers in an everyday PE setting. Limitations include a small and selective study sample, a cross sectional design that did not allow us to compare effects of the two models, and lack of longitudinal data. Because of the cross sectional design, we are unable to determine whether differences between the two groups are due to the classes themselves, or could be explained by pre-existing differences between students who chose to enroll in one program over the other. The measured behaviors could also be confounded with the PE class students were attending. In addition, the majority of the students were girls, and all vocational study programs were not included. A small number of boys limit the possibility to analyze gender differences. Finally, the questionnaire and objective PA were not measured simultaneously, and the period of PA assessment was long due to limited access to PA monitors. Thus the internal and external validity of the study is limited.

The present has provided increased knowledge about important factors when planning future PE programs according to the preferences and expectations of students. In line with the present study, a study from van Sluijs and Kriemler [23] has confirmed that when designing PE programs, students' background, preferences and physical activity experiences has to be kept in mind as a prerequisite for PE programs that generate fun and support motivation for enjoying regular PA. In the present study, students participating in the focus groups also suggested to include theory, by providing information concerning the relationship between lifestyle habits and physical and mental health. Thus it should be possible to take advantage of PE as an opportunity to inspire adolescents to adopt and maintain a healthy lifestyle. The probability of success may depend competent PE teachers who provide PE the students perceive as meaningful and fun, and to include the students' preferences in program development.

\section{Conclusion}

The results indicated that students selecting "Motion enjoyment" accrued less steps/day, reported a higher screen time, a more irregular meal pattern and a higher number were current smokers compared to students selecting "Sports enjoyment". Program evaluation revealed that both groups of students highlighted the importance of having competent PE teachers, being able to influence on the content of the PE program and that PE classes should include a variation of fun activities.

\section{Appendix 1}

\section{Interview guide}

How are your previous experiences with physical education and physical activity?

- Enjoyment

- Participation

- Leisure-time physical activity

- Physical education in junior high school

How are your experiences with physical education in high school so far?

- Enjoyment

- Participation

What have you learned in physical education?

- Knowledge of health and physical activity?

- «Technical skills »?

Some students need tailoring to be able to participate. How do you think this works?

- What is wanted?

- What is possible to do?

How should the education be to make most students enjoying to participate?

- Motion enjoyment

- What do you thing about our PE model?

\section{Appendix 2}

Consolidated criteria for reporting qualitative studies (COREQ): 32-item checklist

Developed from:

Tong A, Sainsbury P, Craig J. Consolidated criteria for reporting qualitative research (COREQ): a 32-item checklist for interviews and focus groups. International Journal for Quality in Health Care. 2007. Volume 19, Number 6: pp. 349-357 


\begin{tabular}{|c|c|c|}
\hline No. Item & Guide questions/description & Response \\
\hline \multicolumn{3}{|l|}{ Domain 1: Research team and reflexivity } \\
\hline \multicolumn{3}{|l|}{ Personal Characteristics } \\
\hline 1. Interviewer/facilitator & $\begin{array}{l}\text { Which author/s conducted the } \\
\text { interview or focus group? }\end{array}$ & $\begin{array}{l}\text { EA, and GR conducted the focus groups supported } \\
\text { by an assistant (CSO) }\end{array}$ \\
\hline 2. Credentials & $\begin{array}{l}\text { What were the researcher's } \\
\text { credentials? E.g. PhD, MD }\end{array}$ & EA: MD, PhD. GR: MSc, PhD. CSO: MSC \\
\hline 3. Occupation & $\begin{array}{l}\text { What was their occupation at the } \\
\text { time of the study? }\end{array}$ & $\begin{array}{l}\text { EA: Public health officer. GR: Professor. } \\
\text { CSO: Physiotherapist }\end{array}$ \\
\hline 4. Gender & Was the researcher male or female? & Female: GR, CSO. Male: EA \\
\hline 5. Experience and training & $\begin{array}{l}\text { What experience or training did the } \\
\text { researcher have? }\end{array}$ & $\begin{array}{l}\text { The group of researchers had experience with } \\
\text { qualitative and quantitative research methods } \\
\text { based on several previous research projects. }\end{array}$ \\
\hline \multicolumn{3}{|l|}{ Relationship with participants } \\
\hline 6. Relationship established & $\begin{array}{l}\text { Was a relationship established prior } \\
\text { to study commencement? }\end{array}$ & No \\
\hline $\begin{array}{l}\text { 7. Participant knowledge of the } \\
\text { interviewer }\end{array}$ & $\begin{array}{l}\text { What did the participants know about } \\
\text { the researchers? e.g. personal goals, } \\
\text { reasons for doing the research }\end{array}$ & $\begin{array}{l}\text { The participants knew that members of the } \\
\text { research group were interested in adolescent } \\
\text { health, and had signed an informed consent } \\
\text { prior to participation }\end{array}$ \\
\hline 8. Interviewer characteristics & $\begin{array}{l}\text { What characteristics were reported about } \\
\text { the inter viewer/facilitator? e.g. Bias, } \\
\text { assumptions, reasons and interests in the }\end{array}$ & $\begin{array}{l}\text { The interviewers represented different professions: } \\
\text { Medicine (EA), physiotherapy (CSO) and nursing } \\
\text { science (GR) }\end{array}$ \\
\hline
\end{tabular}

Domain 2: study design research topic

\section{Theoretical framework \\ 9. Methodological orientation and Theory}

Participant selection

10. Sampling

11. Method of approach

12. Sample size

13. Non-participation

\section{Setting}

14. Setting of data collection

15. Presence of non-participants

16. Description of sample
What methodological orientation was stated to underpin the study? e.g. grounded theory, discourse analysis, ethnography, phenomenology, content analysis

How were participants selected? e.g. purposive, convenience, consecutive, snowball

How were participants approached? e.g. face-to-face, telephone, mail, email

How many participants were in the study?

How many people refused to participate or dropped out? Reasons?

Where was the data collected? e.g. home, clinic, workplace

Was anyone else present besides the participants and researchers?

What are the important characteristics of the sample? e.g. demographic data, date
Systematic Text Condensation represents a hermeneutic phenomenological approach. Self-determination theory was used as a theoretical framework

PE teachers invited a convenient sample of students participating in the study to take part in focus group interviews

The participants were invited face-to-face by their $P E$ teacher an encouraged to participate in focus group interviews

We arranged 4 focus groups:

Six boys attending "Motion enjoyment"

Six girls attending "Motion enjoyment"

Five girls attending "Sports enjoyment"

Six boys attending "Sports enjoyment"

Two boys attending "Sports enjoyment", one girl attending "Sports enjoyment", 2 girls attending "Motion enjoyment" and two boys attending "Motion enjoyment" did not show up

The interviews took place in meeting rooms at the schools during school hours

No, only the researcher or the research assistant

Male and female students attending to both PE programs participated 
(Continued)

\begin{tabular}{|c|c|c|}
\hline \multicolumn{3}{|l|}{ Data collection } \\
\hline 17. Interview guide & $\begin{array}{l}\text { Were questions, prompts, guides provided } \\
\text { by the authors? Was it pilot tested? }\end{array}$ & $\begin{array}{l}\text { The interview guide is enclosed with the } \\
\text { manuscript. }\end{array}$ \\
\hline 18. Repeat interviews & $\begin{array}{l}\text { Were repeat inter views carried out? } \\
\text { If yes, how many? }\end{array}$ & No \\
\hline 19. Audio/visual recording & $\begin{array}{l}\text { Did the research use audio or visual recording } \\
\text { to collect the data? }\end{array}$ & The interviews were audiotaped \\
\hline 20. Field notes & $\begin{array}{l}\text { Were field notes made during and/or after } \\
\text { the inter view or focus group? }\end{array}$ & $\begin{array}{l}\text { Short field notes were made after } \\
\text { the interviews }\end{array}$ \\
\hline 21. Duration & $\begin{array}{l}\text { What was the duration of the inter views or } \\
\text { focus group? }\end{array}$ & $\begin{array}{l}\text { The duration of the focus group } \\
\text { interviews were } 45-90 \text { min. }\end{array}$ \\
\hline 22. Data saturation & Was data saturation discussed? & $\begin{array}{l}\text { Data saturation was discussed and } \\
\text { considered sufficient to perform the analysis }\end{array}$ \\
\hline 23. Transcripts returned & $\begin{array}{l}\text { Were transcripts returned to participants for } \\
\text { comment and/or correction? }\end{array}$ & No \\
\hline \multicolumn{3}{|l|}{ Domain 3: analysis and findings } \\
\hline \multicolumn{3}{|l|}{ Data analysis } \\
\hline 24. Number of data coders & How many data coders coded the data? & $\begin{array}{l}\text { Two researchers (EA and GR) coded } \\
\text { the data }\end{array}$ \\
\hline 25. Description of the coding tree & $\begin{array}{l}\text { Did authors provide a description of the } \\
\text { coding tree? }\end{array}$ & $\begin{array}{l}\text { The headlines and subtitles in the results } \\
\text { presentation represent the final coding tree. }\end{array}$ \\
\hline 26. Derivation of themes & $\begin{array}{l}\text { Were themes identified in advance or } \\
\text { derived from the data? }\end{array}$ & Themes were derived from the data. \\
\hline 27. Software & $\begin{array}{l}\text { What software, if applicable, was used to } \\
\text { manage the data? }\end{array}$ & $\begin{array}{l}\text { We used NVivo }{ }^{\oplus} \text { for Mac version 10.2.1 to } \\
\text { assist analysis. }\end{array}$ \\
\hline 28. Participant checking & $\begin{array}{l}\text { Did participants provide feedback on the } \\
\text { findings? }\end{array}$ & No \\
\hline \multicolumn{3}{|l|}{ Reporting } \\
\hline 29. Quotations presented & $\begin{array}{l}\text { Were participant quotations presented to } \\
\text { illustrate the themes/findings? Was each } \\
\text { quotation identified? e.g. participant number }\end{array}$ & $\begin{array}{l}\text { Yes. Gender and PE program identified the } \\
\text { participants }\end{array}$ \\
\hline 30. Data and findings consistent & $\begin{array}{l}\text { Was there consistency between the data } \\
\text { presented and the findings? }\end{array}$ & Yes \\
\hline 31. Clarity of major themes & $\begin{array}{l}\text { Were major themes clearly presented in } \\
\text { the findings? }\end{array}$ & Yes \\
\hline 32. Clarity of minor themes & $\begin{array}{l}\text { Is there a description of diverse cases or } \\
\text { discussion of minor themes? }\end{array}$ & $\begin{array}{l}\text { Several diverse cases and minor themes } \\
\text { are described in the results chapter }\end{array}$ \\
\hline
\end{tabular}

\section{Abbreviations}

$\mathrm{Cl}$ : Confidence interval; MVPA: Moderate-to-vigorous intensity physical activity; OR: Odds ratio; PA: Physical activity; PE: Physical education; SDT:

Self-determination theory; WHO: World Health Organization

\section{Acknowledgements}

We are grateful to all the students who participated in this study, to the PE teachers who made this intervention and study possible, and to Christina S. Omfjord who assisted us during data collection.

\section{Funding}

The study was funded by the Regional Research Fund Agder.

\section{Availability of data and materials}

The data are available from the corresponding author on reasonable request.

\section{Authors' contributions}

All authors participated in planning and designing the study. EA and GR conducted the qualitative study and analyzed qualitative data. SB and THS analyzed quantitative data. EA and THS drafted the manuscript. All authors critically revised and approved the final manuscript.

\section{Competing interests}

The authors declare that they have no competing interests.

\section{Consent for publication}

The manuscript does not contain any data that can be linked to a person directly or indirectly. The written consent to participate in the study included information about publication.

\section{Ethics approval and consent to participate}

The study was approved by the Norwegian Social Science Data Services (35639) and by the Regional Committee for Medical and Health Research Ethics, South-East B (2013/1235). Written consent was obtained from the students or the students' parents/legal guardian for the students under 16 years. 


\section{Author details}

Department of Global Public Health and Primary Care, University of Bergen Bergen, Norway. ${ }^{2}$ Department of Health and Nursing Sciences, University of Agder, Kristiansand, Norway. ${ }^{3}$ Department of Public Health, Sport and Nutrition, University of Agder, Kristiansand, Norway.

Received: 12 August 2016 Accepted: 1 March 2017

Published online: 10 March 2017

\section{References}

1. Hallal PC, Andersen LB, Bull FC, Guthold R, Haskell W, Ekelund U. Global physical activity levels: surveillance progress, pitfalls, and prospects. Lancet. 2012;380(9838):247-57.

2. The Norwegian Directorate of Health. Fysisk aktivitet blant 6-, 9- og 15åringer i Norge. Resultater fra en kartlegging i 2011 (Physical activity among 6-, 9- and 15-year olds in Norway. Results from a mapping in 2011). Oslo: The Norwegian Directorate of Health; 2012.

3. Ekeland E, Heian F, Hagen KB, Abbott J, Nordheim L. Exercise to improve self-esteem in children and young people. Cochrane Database Syst Rev. 2004;(1):Cd003683. doi:10.1002/14651858.CD003683.pub2.

4. Larun L, Nordheim LV, Ekeland E, Hagen KB, Heian F. Exercise in prevention and treatment of anxiety and depression among children and young people. Cochrane Database Syst Rev. 2006;(3):Cd004691. doi:10.1002/ 14651858.CD004691.pub2.

5. Singh A, Uijtdewilligen L, Twisk JW, van Mechelen W, Chinapaw MJ. Physical activity and performance at school: a systematic review of the literature including a methodological quality assessment. Arch Pediatr Adolesc Med 2012;166(1):49-55.

6. Stea TH, Torstveit MK. Association of lifestyle habits and academic achievement in Norwegian adolescents: a cross-sectional study. BMC Public Health. 2014;14:829.

7. Telama R, Yang X, Leskinen E, Kankaanpaa A, Hirvensalo M, Tammelin T, Viikari JS, Raitakari OT. Tracking of physical activity from early childhood through youth into adulthood. Med Sci Sports Exerc. 2014;46(5):955-62.

8. Lee IM, Shiroma EJ, Lobelo F, Puska P, Blair SN, Katzmarzyk PT. Effect of physical inactivity on major non-communicable diseases worldwide: an analysis of burden of disease and life expectancy. Lancet. 2012;380(9838):219-29.

9. Oldridge NB. Economic burden of physical inactivity: healthcare costs associated with cardiovascular disease. Eur J Cardiovasc Prev Rehabilitation. 2008;15(2):130-9.

10. St Leger L. Schools, health literacy and public health: possibilities and challenges. Health Promot Int. 2001;16(2):197-205.

11. Dobbins M, Husson H, DeCorby K, LaRocca RL. School-based physical activity programs for promoting physical activity and fitness in children and adolescents aged 6 to 18. Cochrane Database Syst Rev. 2013;2:Cd007651.

12. Lai SK, Costigan SA, Morgan PJ, Lubans DR, Stodden DF, Salmon J, Barnett LM. Do school-based interventions focusing on physical activity, fitness, or fundamental movement skill competency produce a sustained impact in these outcomes in children and adolescents? A systematic review of follow-up studies. Sports Med (Auckland, NZ). 2014;44(1):67-79.

13. Trudeau F, Laurencelle $L$, Shephard RJ. Tracking of physical activity from childhood to adulthood. Med Sci Sports Exerc. 2004;36(11):1937-43.

14. Ryan RM, Deci EL. Self-determination theory and the facilitation of intrinsic motivation, social development, and well-being. Am Psychologist. 2000;55(1):68-78.

15. Lewis K. Pupils' and teachers' experiences of school-based physical education: a qualitative study. BMJ Open. 2014;4(9):e005277.

16. Bauman AE, Reis RS, Sallis JF, Wells JC, Loos RJ, Martin BW. Correlates of physical activity: why are some people physically active and others not? Lancet. 2012:380(9838):258-71.

17. Hills AP, Dengel DR, Lubans DR. Supporting public health priorities: recommendations for physical education and physical activity promotion in schools. Prog Cardiovasc Dis. 2015;57(4):368-74.

18. Naylor PJ, Nettlefold L, Race D, Hoy C, Ashe MC, Wharf Higgins J, McKay HA Implementation of school based physical activity interventions: A systematic review. Prev Med. 2015:72c:95-115.

19. Camacho-Minano MJ, LaVoi NM, Barr-Anderson DJ. Interventions to promote physical activity among young and adolescent girls: a systematic review. Health Educ Res. 2011;26(6):1025-49.
20. Murillo Pardo B, Garcia Bengoechea E, Generelo Lanaspa E, Bush PL, Zaragoza Casterad J, Julian Clemente JA, Garcia Gonzalez L. Promising school-based strategies and intervention guidelines to increase physical activity of adolescents. Health Educ Res. 2013;28(3):523-38.

21. Ntoumanis N. Empirical links between achievement goal theory and self-determination theory in sport. J Sports Sci. 2001;19(6):397-409.

22. Taylor IM, Ntoumanis N, Standage M, Spray CM. Motivational predictors of physical education students' effort, exercise intentions, and leisure-time physical activity: a multilevel linear growth analysis. J Sport Exerc Psychol. 2010;32(1):99-120

23. van Sluijs EM, Kriemler S. Reflections on physical activity intervention research in young people - dos, don'ts, and critical thoughts. Int J Behav Nutr Phys Act. 2016;13(1):25.

24. Ministry of Education and Research. Curriculum for physical education. Oslo: Ministry of Education and Research; 2015: p 2

25. WHO. Global status report on noncommunicable diseases 2014. Geneva: WHO; 2014.

26. The School Portal [https://skoleporten.udir.no/]. Accessed 4 Mar 2017.

27. Abildsnes E, Stea TH, Berntsen S, Omfjord CS, Rohde G. Physical education Teachers' and public health Nurses' perception of Norwegian high school Students' participation in physical education - a focus group study. BMC public health. 2015:15:1295.

28. Teddlie C, Tashakkori A. Foundations of Mixed Methods Research: Integrating quantitative and qualitative approaches in the social and behavioral sciences. Thousand Oaks: Sage Publications Inc.; 2009.

29. Abildsnes E, Stea TH, Berntsen S, Omfjord CS, Rohde G. Physical education Teachers' and public health Nurses' perception of Norwegian high school Students' participation in physical education - a focus group study. BMC Public Health. 2015;15:1295.

30. Berntsen S, Hageberg R, Aandstad A, Mowinckel P, Anderssen SA Carlsen KH, Andersen LB. Validity of physical activity monitors in adults participating in free-living activities. Br J Sports Med. 2010;44(9):657-64.

31. Calabro MA, Lee JM, Saint-Maurice PF, Yoo H, Welk GJ. Validity of physical activity monitors for assessing lower intensity activity in adults. Int J Behav Nutr Phys Act. 2014;11:119.

32. Calabro MA, Stewart JM, Welk GJ. Validation of pattern-recognition monitors in children using doubly labeled water. Med Sci Sports Exerc. 2013;45(7):1313-22

33. Stalesen J, Vik FN, Hansen BH, Berntsen S. Comparison of three activity monitors for estimating sedentary time among children. BMC Sports Sci Med Rehabilitation. 2016;8:2.

34. Matthews CE, Hagstromer M, Pober DM, Bowles HR. Best practices for using physical activity monitors in population-based research. Med Sci Sports Exerc. 2012:44(1 Suppl 1):S68-76.

35. Malterud K. Systematic text condensation: a strategy for qualitative analysis. Scand J Public Health. 2012:40(8):795-805.

36. Miller WL, Crabtree BJ. Clinical research. A multimethod typology and qualitative roadmap. In: Doing Qualitative Research. 2nd ed. Thousand Oaks: Sage; 1999. p. 20-4.

37. Tong A, Sainsbury P, Craig J. Consolidated criteria for reporting qualitative research (COREQ): a 32-item checklist for interviews and focus groups. Int J Qual Health Care. 2007;19(6):349-57.

38. Kwon S, Janz KF, Letuchy EM, Burns TL, Levy SM. Developmental trajectories of physical activity, sports, and television viewing during childhood to young adulthood: lowa Bone Development Study. JAMA Pediatr. 2015; 169(7):666-72

39. Leech RM, McNaughton SA, Timperio A. The clustering of diet, physical activity and sedentary behavior in children and adolescents: a review. Int $J$ Behav Nutr Phys Act. 2014:11:4

40. Torstveit MK, Aagedal-Mortensen K, Stea TH. More than half of high school students report disordered eating: a cross sectional study among Norwegian boys and girls. PLoS One. 2015;10(3):e0122681.

41. Anderssen N, Wold B, Torsheim T. Tracking of physical activity in adolescence. Res Q Exerc Sport. 2005;76(2):119-29.

42. Bagøien TE, Halvari $H$, Nesheim $H$. Self-determined motivation in physical education and its links to motivation for leisure-time physical activity, physical activity, and well-being in general. Percept Mot Skills. 2010;111(2):407-32 